\title{
Derleme/Review
}

\section{Premenstrual Sendromda Ağrı Yönetimi}

\section{Pain Management in Premenstrual Syndrome}

\author{
Hatice Sarı Çetin ${ }^{1}$ (iD) Nülüfer Erbil ${ }^{2}$ \\ ${ }^{1}$ Fatsa Lokman Hekim Mesleki ve Teknik Anadolu Lisesi, Fatsa/Ordu, TÜRKIYYE \\ ${ }^{2}$ Ordu Üniversitesi Sağlık Bilimleri Fakültesi, Doğum ve Kadın Hastalıkları Hemşireliği Anabilim Dalı, Ordu, TÜRKIYYE \\ Geliş tarihi/ Date of receipt: 24/02/2020 Kabul tarihi/ Date of acceptance: 26/04/2020 \\ (C) Ordu University Faculty of Health Sciences, Department of Nursing, TURKEY, Published online 30/09/2020
}

ÖZ

Premenstrual sendrom (PMS) menstrual siklusun geç luteal fazında görülen, çoğu siklusta tekrarlayan, menstruasyonla birlikte hızla düzelen, foliküler fazda en az bir hafta görülmeyen, bilişsel, fiziksel, somatik ve duygusal davranış değişikliklerinin görüldüğü bir tablodur. Ağrı PMS'de en sık görülen belirtilerden biridir. Ağrı özellikle karın, bel, sırt, baş bölgesi ve memeler ile kas ve eklemlerde görülür. PMS'de ağrı kontrolünde, kolaylıkla uygulanabilir olması, kolay erişilebilmesi ve hızlı etki göstermesi sebebiyle ilaç tedavisi en sık tercih edilen yöntemdir. Fakat bu ilaçların fazla bir şekilde ve bilinçsiz kullanılması hem kişinin sağlığına zarar vermekte hem de kişi ve ülke ekonomisine yük getirmektedir. Özellikle narkotik analjeziklerin her seferinde daha yüksek dozda alınması sebebiyle tolerans gelişmesi gibi olumsuz etkileri de vardır. Farmakolojik yöntemlerin ortaya çıkardığı ekonomik yükü ortadan kaldırmak ve kişi üzerindeki yan etkilerini yok etmek için farmakolojik olmayan yöntemler kullanılabilir. Bu yöntemler; aromaterapi, hipnoz, masaj, refleksoloji, sıcak uygulama, akupunktur, yoga, dikkati başka yöne çekme, müzik dinleme, meditasyon, terapötik dokunma ve transkütan elektriksel sinir stimülasyonudur. Bunun yanında özellikle hayıt otu, sarı kantoran otu ve mabet ağacı bitkisi de PMS'de ağr kontrolünde tercih edilebilecek bitkisel ürünlerdir. Premenstrual semptomda ağrı ile baş etmede, PMS'nin bir sorun olduğu, gerektiğinde uzmana başvurma bilinci kazandırmaya yönelik eğitim verilmelidir. Böylece, PMS semptomlarının azaltılması ya da önlenmesinde bireyin kendi sorumluluğunu üstlenmesi ve kendi bakımına katılımı sağlanmış olacaktır.

Anahtar Kelimeler: Premenstrual sendrom, ağr1, ağr1 yönetimi.

\begin{abstract}
Premenstrual syndrome is a combination showing the changes in cognitive, physical, somatic and emotional behavior seen in the late luteal phase of the menstrual cycle, recurrent in most cycles, rapidly resolving with menstruation, and not seen at least one week in the follicular phase. Many women with premenstrual syndrome have physical, behavioral, and psychological symptoms. Pain in premenstrual syndrome are seen in the abdomen, waist, back, head, breast, joints, muscles. In the management of pain in premenstrual syndrome, drug treatment is the most commonly used method because it is easy to apply, easy to access, and fast acting. However, excessive use of these medicines and unconsciousness both damage the health of the person and cause a burden on the person and the country's economy. Particularly, narcotic analgesics have negative effects such as tolerance development because they are taken at higher doses each time. Non-pharmacological methods can be used to remove the economic burden of pharmacological methods and eliminate side effects on the person. These methods are aromatherapy, hypnosis, massage, reflexology, hot application, acupuncture, yoga, distraction, music listening, meditation, therapeutic touch and transcutaneous electrical nerve stimulation. Beside this, especially herbaceous plants, yellow centaury herbaceous plants and garden plants are also herbal products that can be preferred in pain management in premenstrual syndrome. In coping with pain in premenstrual symptom, training should be given to raise awareness of the fact that PMS is a problem and that it is necessary to consult a specialist.
\end{abstract}

Keywords: Premenstrual syndrome, pain, pain management.

ORCID IDs of the authors: HSÇ: 0000-0002-1720-3598, NE: 0000-0003-3586-6237

Sorumlu yazar/Corresponding author: Hatice Sarı Çetin

Fatsa Lokman Hekim Mesleki ve Teknik Anadolu Lisesi, Fatsa/Ordu, TÜRKIYYE

e-posta/e-mail: sari_hatice5 @ hotmail.com

Bu çalışma, 23-24 Mart 2018 tarihleri arasında İstanbul'da yapılan 1. Uluslararası II. Ulusal Kadın Să̆lı̆̆ Hemşireliği Kongresinde sözel bildiri olarak sunulmuştur.

Atıf/Citation: Sarı Çetin H, Erbil N. (2020) Premenstrual sendromda ağrı yönetimi. Ordu Üniversitesi Hemşirelik Çalışmaları Dergisi, 3(2), 202-210. DOI:10.38108/ouhcd.693294 


\section{Giriş}

Menstruasyon, her ay düzenli olarak tekrarlayan, kadınların yaşamlarının 30-35 y1lını içine alan fizyolojik bir süreçtir (Gençdoğan, 2006). Premenstrual sendrom menstrual siklusun geç luteal fazında görülen, çoğu siklusta tekrarlayan, menstruasyonla birlikte hızla düzelen, folikül fazında en az bir hafta görülmeyen, bilişsel, fiziksel, somatik ve duygusal davranış değişikliklerinin görüldüğü bir tablodur (Taşkın, 2016).

Premenstrual sendrom, ilk defa 1931 y1lında Frank tarafından tanımlanmış, menstruasyondan önceki 7-10 gün süresince görülen ve kanamayla birlikte hafifleyen huzursuzluk, baş ağrısı, kilo artış1, ödem ve gerilim yakınmaları olan 15 kadının gözlemi sonucunda, bu durum "premenstrual gerginlik" olarak adlandırılmıştır. Ayrıca Frank bu semptomların görülmesinin nedenini over yetersizliği olarak açıklamıştır (Frank, 1931). PMS terimi ise ilk kez 1953 yılında Greene ve Dalton tarafından kullanmış olup, Amerikan Ulusal Akıl Sağlığı Enstitüsü'nce ilk kez 1983 yılında tanımlanmıştır. DSM-III-R'de 'geç luteal faz disforik bozukluğu" olarak tanımlanan bu durum, DSM-IV'de "premenstrual disforik bozukluk" (PMDB) olarak adlandırılmıştır (Çatakoğlu, 2016). Dünya Sağlık Örgütü, Sağlıkla İlgili Problemlerin ve Hastalıkların Uluslararası İstatistiksel Sinıflandırılması Onbirinci Revizyonuna (ICD-11) Disforik Bozukluğu (PMDB) eklemiştir. ICD-11, premenstrual disforik bozukluğu (PMDB) "duygudurum belirtileri paterni (depresif ruh hali, sinirlilik), somatik belirtiler (uyuşukluk, eklem ağrısı, aşırı yeme) veya bilişsel belirtiler (konsantrasyon zorlukları, unutkanlık) şeklinde tanımlamıştır (Reed ve ark., 2019).

Premenstrual sendromun nedeni tam olarak bilinmemektedir. Nedenine ilişkin farklı teoriler vardır. $\mathrm{Bu}$ teoriler, östrojenprogesteron dengesizlikleri, siv1 retansiyonu, prostaglandinlerin aşırı salgılanması, prolaktin salgısındaki değişiklikler, endojen endorfinlerin yetersizliği, renin-anjiotensinaldesteron dengesizlikleri, mineral ve vitamin yetersizliği, troid fonksiyon bozukluğu, hipoglisemi, ve psikososyal faktörlerdir (Öztürk ve Tanrıverdi, 2010).

Premenstrual sendromlu kadınlarda fiziksel, davranışsal ve psikolojik birçok semptom görülmektedir (Erbil ve ark., 2010). Fiziksel belirtiler; memelerde hassasiyet ve dolgunluk, abdominal şişkinlik ve ağrı, konstipasyon, kilo alma, mide bulantısı, diyare, ödem, özel besinlere karşı ilgi, akne, yorgunluk, sıcak basması, uykusuzluk, eklem ve kas ağrısı ve aşırı uyku halidir (Öztürk ve Tanrıverdi, 2010). Davranışsal belirtiler; cinsel istekte değişiklik, çalışma alışkanlığında değişiklik, insan ilişkilerinden kaçma, kavgaya eğilim ve ağlama nöbetleridir. Psikolojik belirtiler; kızıınlı, yetersizlik hissi, depresyon, anksiyete, unutkanlık, huzursuzluk, suçluluk hissi, paranoya, ses ve 1şığa aşırı duyarlılıktır. İntihar düşüncesi, şiddete eğilim ve psikoz da görülebilir (Öztürk ve Tanrıverdi, 2010).

Premenstrual sendromda görülen semptomlardan biri olan ağrı ile baş etmede kullanılan farmakolojik ve nonfarmakolojik yöntemler hakkında bilgi verilmesi ve ağrı yönetimi konusunda sağlık personelinin rolünün belirtilmesi bu derlemede amaçlanmıștır. Özellikle sağlık personeli tarafindan kanita dayalı nonfarmakolojik yöntemlerin kullanılması ile, sağlık bakımının kalitesini yükseltmek, hasta bakım sonuçlarında ve klinik uygulamalarda fark yaratmak, hasta memnuniyetini yükseltmek ve bakımı standardize etmek mümkün olabilmektedir.

Premenstrual sendromun nedeninin tam olarak bilinememesinden dolayı tedavide uzun yıllar başarı elde edilememiş ve birçok semptomatik ve nonspesifik tedavi yöntemleri denenmiştir. Günümüzde de premenstrual sendrom için farmakolojik ve nonfarmakolojik birçok tedavi uygulanmaktadır. Farmakolojik tedaviler; progesteron tedavisi, oral kontraseptifler, danazol tedavisi, GNRH agonistleri, diüretikler, B6 vitamini takviyesi, kalsiyum ve magnezyum tedavisi, analjezikler, anksiyolitikler ve antidepresanlardir. Nonfarmakolojik tedaviler ise; refleksoloji, yoga, masaj, aromaterapi, kayropraksi, fitoterapi ve akupunkturdur. 
$\mathrm{Bu}$ tedavi yöntemlerinin başarısında tabi ki PMS'nin derecesi de önem kazanmaktadır. PMS hafif veya orta derecede ise yaşam tarzı değişiklikleri ve diyet ile iyileşme görülürken, semptomlar günlük hayatı olumsuz etkilemeye başlamışsa farmakolojik tedavi önerilmektedir (Abay ve Kaplan, 2019).

Tedavinin ilk basamağını, premenstrual sendromun bir problem olduğunun hasta tarafından kabul edilmesi oluşturmaktadır. Premenstrual sendrom tek bir rahatsızlık olarak düşünülmemeli, farklı problemlerin bütünü olarak ele alınmalıdır. Böylece premenstrual semptomlar için en etkili tedavi modeli uygulanabilir. Tedavide, Keye tarafindan ortaya konulan ve genel olarak kabul edilen metod "biyopsikososyal yaklaşım"dır. $\mathrm{Bu}$ yaklaşım, yanlış düşüncelerin ve korkuların giderilmesi ve yaşam tarzında değişiklik yapılmasıdır (Arslan ve Dökmeci, 1999). Bu nedenle sağlık çalışanları, kadınlara premenstrual sendrom hakkında eğitim vererek, yaşam biçimi ve farmakoterapi hakkında danışmanlık yaparak semptomlarla baş etmelerini sağlamaya yardımcı olmalıdır (Öztürk ve Tanrıverdi, 2010).

\section{Ağrı}

İnsanların yaşadığ 1 ortak deneyimlerden olan ağrı, hem karmaşık hem de bireyin yaşam kalitesini etkileyen hoş olmayan bir duygudur (Özveren ve Uçar, 2009; Özveren ve ark., 2016). Ağrıyı sadece biyolojik olarak açıklamak mümkün değildir. Ağrının doku harabiyetine karşı oluşan bir reaksiyon olarak ortaya çıktığı düşünülüyor olmasına rağmen inançlar, emosyonel özellik, genetik, kültürel ve bireysel özelliklerde ağrıyı etkilemektedir (Koçoğlu ve Özdemir, 2011). Özellikle ağrının bireysel özelliklerden etkilenmesi onun tanımlanması ve anlaşılmasını güçleştirmektedir (Özveren ve Uçar, 2009). Uluslararası Ağrı Araştırmaları Derneği (IASP) (2012) ağriyı, vücudun herhangi bir bölgesinden kaynaklanan, gerçek ya da olası bir doku harabiyeti ile birlikte bulunan, kişinin geçmişteki deneyimleri ile ilgili hoş olmayan emosyonel ve duyusal bir davranış şekli olarak tanımlamıştır.
Bireylerin ağrı deneyiminde yaş, eğitim düzeyi, cinsiyet, sosyo-ekonomik ve kültürel faktörlerin de rol oynadığı görülmektedir. Ayrıca ağrı deneyiminde bireysel özelliklerin önemli olduğu ve özellikle kişilerin ağrıyı ifade etme şekli, ağrı görülen bölge, ağrının şiddeti, ağriyla ilgili inançlar ve baş etme metotlarının da ağn deneyimlerini etkilediği görülmektedir (Koçoğlu ve Özdemir, 2011). Ayrıca literatürde ağrı eşiğinin kişiden kişiye değişebileceği hatta aynı bireyde zamanla da değişebileceği; uykusuzluk, korku, çaresizlik, yorgunluk, öfke, depresyon, iş kaybı, stres, ailevi kaygıların ağrı eşiğini düşüren faktörler olduğu; ruhsal durumun iyi olması, dinlenme, gevşeme, sosyal kişilik, yeterli uykunun ise ağr1 eşiğini yükselten faktörler olduğundan bahsedilmektedir (Çöçelli ve ark., 2008).

Bunun yanında bazı kültürlerde ağrı bir statü kaynağı olarak algılanırken, bazılarında ise bir ceza olarak algılanmaktadır. Kültürel olarak hatta bireysel olarak farklı algılanan ağrının kontrol altına alınması bireylerin yaşam kalitesini arttırmada önemli rol oynar (Koçoğlu ve Özdemir, 2011). Çünkü kişilerin yaşadıkları ağrı, sosyal ve aile yaşantılarını, uyku düzenlerini, iş verimliliklerini ve özellikle günlük yaşam aktivitelerini etkileyerek yaşam kalitelerini düşürür (Özveren ve Uçar, 2009).

\section{Premenstrual Sendromda Ağrı}

Premenstrual sendromda en sik görülen belirtilerden biri de ağrıdır. Ağrı özellikle karın, bel, baş bölgesi, memeler, kas ve eklemlerde görülür (Öztürk ve Tanrıverdi, 2010). Adölesan ve üniversite öğrencileri üzerinde yapılan araştırmalarda premenstrual dönemde ağrı görülme sıklığı \%7.9 ile \%96.5 arasında değişmektedir (Eğicioğlu ve ark., 2014; Erbil ve ark., 2010; Iş1k ve ark.,2016).

\section{Premenstrual Sendromda Yönetiminde Kullanılan Yöntemler \\ Yapılan birçok araştırma kadınların ağrının kontrolünde ilk olarak farmakolojik yöntemleri kullandığını göstermektedir.}


Premenstrual sendromla baş etmede analjezik kullanma oranını, Kırcan ve arkadaşları (2012) \%47.6, Oskay ve arkadaşları (2008) \%53.4, Keskin ve arkadaşları (2016) \%61.4, Kısa ve arkadaşları (2012) \%48.7, Erbil ve ark. (2011) \%32.5, ve Eğicioğlu ve arkadaşları (2014) ise \%42.1 olarak saptamışlardır. Bu konuda yapılan farklı bir çalışma ise, premenstrual dönemde ağrı ile baş etmek için ağrı kesici ilaç alma dışındaki yöntemleri kadınların etkili kullanmadıklarını göstermektedir (Oskay ve ark., 2008).

PMS de ağrı yönetiminde farmakolojik yöntemlerin yanı sıra nonfarmakolojik yöntemlerinde kullanıldığını araştırmalar göstermektedir. Yapılan bir çalışmada, premenstrual sendromda ağrı ile baş etmede, kadınların \%43.3'ünün istirahat ettiği ve \%10.4'ünün sıcak uygulama yaptığ1 bulunmuştur (Eğicioğlu ve ark., 2014). Erbil ve ark. (2011) premenstrual sendrom semptomlarıyla baş etmek için kadınların, istirahat etme $(\% 27.5)$, sicak uygulama (\%12.9), yürüyüş (\%4.4), bitkisel çay (\%2.9) ve masaj (\%1.9) yöntemlerini kullandığını belirtmiştir. Ayrıca Oskay ve arkadaşları (2008) öğrencilerin \%23.3'ünün, Keskin ve arkadaşları (2016) ise öğrencilerin \%50.6'sının premenstrual dönemdeki ağrı ile baş etmede uyumayı tercih ettiklerini bulmuştur.

Kolaylıkla uygulanabilir olması, kolay erişilebilmesi ve hızlı etki göstermesi nedeniyle, premenstrual sendromda analjezik kullanımı en sık tercih edilen yöntemdir. Fakat bu ilaçların bilinçsiz ve kontrolsüz kullanılması hem kişinin sağlığına zarar verebilmekte, hem de kişi ve ülke ekonomisine yük getirebilmektedir. Özellikle narkotik analjeziklerin her seferinde daha yüksek dozda alınması nedeniyle tolerans gelişmesi gibi olumsuz etkileri de olabilir (Özveren ve Uçar, 2009).

Farmakolojik yöntemlerin ortaya çıkardığ 1 ekonomik yükü ortadan kaldırmak ve kişi üzerindeki yan etkilerini önlemek için PMS'li hastalara ilk olarak önerilmesi gereken nonfarmakolojik yöntemlerdir (Karaca ve Beji, 2015). Bu yöntemler; aromaterapi, masaj, refleksoloji, sicak uygulama, akupunktur, yoga, dikkati başka yöne çekme, kayropraksi ve fitoterapidir (Özveren ve ark., 2016).

Royal College of Obstetricians and Gynaecologists (RCOG) tarafından geliştirilen Premenstruel Semptom Yönetimi Rehber Kılavuzu (2017) ikinci baskısinda bu yöntemler için klinik çalışmalarla ortaya çıkan verilerin sınırlı olduğu ve güçlü olmadığı belirtilmektedir. Ayrıca kadınların bu yöntemlere yönlendirildiğinde doğacak hukuki sorumluluğun yönlendiren sağlık profesyonellerine ait olduğunun ve bazı yöntemlerin özellikle konvansiyonel ilaçlar ile etkileşime girebileceğinin de unutulmaması gerektiğinden bahsedilmektedir.

PMS de ağrı yönetiminde kullanılan yöntemlere bakacak olursak;

Masaj, vücudun yumuşak dokularının elle ya da mekanik olarak uyarılmasıdır. $\mathrm{Bu}$ uygulamayla deride bulunan çevresel reseptörler uyarılmakta ve uyarılar spinal kordla beyne iletilmektedir. Masajin duygusal ve psikolojik olarak da önemli yararları vardır. Masaj, özellikle depresyonu, kas gerginliğini ve anksiyeteyi tedavi etmede yardımcidır (Turan ve ark., 2010). Premenstrual sendrom ile baş etmede masaj yönteminin kullanım oranlarını, Oskay ve arkadaşları (2008) \%26 ve Keskin ve arkadaşları (2016) \%76.8 bulmuşlardır.

Refleksoloji, premenstrual sendromda ağr1 ile baş etmede kullanılan yöntemlerden biridir. Refleksoloji, vücudun özel organ ve bölgelerinin küçük bir aynası kabul edilen kulaklar, eller ve ayaklardaki refleks noktalarının uyarılması anlamına gelir (Stephenson ve Dalton, 2003). Özel el ve parmak teknikleriyle bu refleks noktalarına uygulanan bask1, stresin azaltılmasinı sağlayarak vücutta fizyolojik farklılıklara yol açmaktadır (Turan ve ark., 2010). Bolsoy (2008)'un premenstrual sendromda refleksolojinin etkinliğini incelediği araştırmada deney grubuna refleksoloji, kontrol grubuna nonsteroidal antienflamatuar ilaç (NSAID) tedavisi uygulanmıştır. Sonuçta refleksoloji grubunun premenstrual distres puanlarının, NSAID alan grubun puanlarından istatistiksel olarak anlamlı derecede düşük 
olduğunu saptanmıştır. Hasanpour ve arkadaşları (2019) yaptıkları çalışmada ayak refleksolojisinin premenstrual sendrom semptomlarını hafiflettiğini ve ayrıca her seansta refleksoloji süresinin uzamasının verimliliği arttırdığını saptamıştır.

Akupunktur, tamamlayic1 bir tedavi yöntemidir. Premenstrual sendromda görülen belirtilerin daha hafif geçirilmesinde yardımcı olabilir. Akupunktur çelik, gümüş ve altından yapılmış iğnelerin vücudun belli noktalarına batırılması ile uygulanmakta ve uzun yıllardır hastalıkların tedavisinde kullanılmaktadır (Cabığlu, 2008). Akupunktur bölgelerine batırılan iğnelerle başlayan uyarılar santral sinir sisteminde kortekse gider ve mezensefalondaki gri cevher ve periventriküler bölgedeki nöronlar uyarılarak, ağrı kontrol sistemi harekete geçer. Bunun sonucunda beyin dokusunda ve plazmada beta endorfin, enkefalin, seratonin ve nörepinefrin seviyelerinde artma meydana gelerek analjezik ve antienflematuar etki ortaya çıkar. Cabığlu (2008) akupunkturun özellikle premenstrual sendrom semptomlarından biri olan ağrıyı hafiflettiğini ve geçirmekte etkili olduğundan bahsetmektedir. Jang ve arkadaşları (2014), yaptıkları çalışmada akupunkturun luteal faz ya da foliküler fazda uygulanmasının, PMS semptomlarında, $\% 50$ ve daha fazla azalma gösterdiği saptamışlardır. Armour ve arkadaşları (2018) da derlemelerinde akupunkturun PMS semptomlarını azaltabileceğinden bahsetmektedir.

Akupresur, ağriyı azaltmak amaciyla vücutta akupunktur bölgelerinde yer alan noktalara bası ve ovma benzeri manipülasyonlarla yapılan bir uygulamadır. Akupunkturdan farklı olarak iğne yerine el, parmak ya da ayaklar kullanılarak uygulanan bu yöntemle kaslar gevşetmekte, kan dolaşımı düzenlemekte ve opioid sistem aktive edilmektedir. Ağrı yönetiminde akupresurun amacı, kişinin ağrı şiddetini mümkün olan en üst seviyede azaltarak, ağrı kesici kullanım miktarını azaltmaktır (İskender ve Eren, 2020). Armour ve arkadaşları (2018) derlemelerinde akupresurun PMS semptomlarını azaltabileceğinden bahsetmektedir.
Düzenli Egzersiz, Luteal fazda endorfin salınımının azalmasını engelleyerek PMS belirtilerinin hafiflemesini sağlamaktadır (Öztürk ve Tanrıverdi, 2010). Egzersizin opiat aktivitesini arttırarak şişkinlik ve memede hassasiyet gibi belirtileri azalttığ1 ve duygu durumda iyileşmeyi sağladığı belirtilmektedir. Sağlam ve Orsal (2020), sistematik derlemelerinde, egzersiz türünden bağımsız olarak düzenli egzersizin ağrıyı geçirmede etkili olduğu sonucuna ulaşmışlardır. Dehnavi ve arkadaşları (2018) yaptıkları çalışmalarında 8 haftalık aerobik egzersizinin PMS de görülen baş ağrısının önemli ölçüde azalttığını saptamışlardır.

Yoga, bedeni, zihni ve ruhu tamamen eğiten ve kişinin kendisini tanımasını sağlayan en eski kişisel gelişim yöntemlerindendir (Duyan, 2007). Yoganın özellikle psikolojik ve fiziksel sağlık üzerinde olumlu etkileri olduğuna inanılmaktadır (Ovayolu ve Ovayolu, 2019). PMS'de yoganın etkisinin araştırıldığı birçok araştırmada PMS'nin semptomlarını önemli ölçüde azalttığı özellikle kadınların kendilerini daha iyi hissetmelerini sağladığı görülmüştür (Kamalifard ve ark., 2017; Wu ve ark., 2015; Tsai, 2016). Vaghela ve arkadaşları (2019) yaptıkları çalışmada yoga hareketlerinin PMS de ağrı şiddetini ve semptomlarını önemli ölçüde azalttığını saptamışlardır.

Aromaterapi, premenstrual sendromda ağr1 kontrolünde kadınların tercih ettiği diğer bir yöntemdir. Aromaterapi, ağaçlardan, çiçeklerden ve bitkilerden alınan esansiyel yağların tedavi amacıyla kullanılmasıdır. $\mathrm{Bu}$ yağlar bazen cilt üzerine masaj yağları olarak ya da kişinin burun delikleri altına konan yağlı tülbentten solumaları yoluyla uygulanır. Aromaterapinin ağrıyı önlemeye yardımcı olduğu ve stresi azalttığı düşünülmektedir (Turan ve ark., 2010). Aromaterapide en s1k kullanılan yağlar; çuha çiçeği yağı ve lavanta yağıdır. Çuha çiçeği yağının E vitamininden zengin olduğu ve tedavinin depresyon ve mastaljiyi düzelttiği belirtilmektedir (Bolsoy, 2008). Matsumoto ve arkadaşları (2013), kısa süreli lavanta yağı inhalasyonu ile adet öncesi duygusal belirtilerin hafiflediği ve kısmen parasempatik sinir sistemi aktivitesinin 
iyileşmesine katkıda bulunduğunu belirtmiştir. Heydari ve arkadaşlarının (2018) yaptığg çalışmada Citrus aurantium çiçeği ile yapılan aromaterapinin ve Lotfipur-Rafsanjani ve arkadaşlarının (2018) yaptıkları araştırma da ise tatlı badem yağ 1 ve sardunya esansiyel yağ 1 ile yapilan aromaterapinin PMS semptomlarını iyileştirdiği saptanmıştır.

Kayropraksi (Şiropraksi, Chiropractic), eklemlerin, kas-iskelet sistemi ve vertebraların biyomekaniksel duruşu üzerine sublukasyonlarını ve disfonksiyonlarını inceleyen ve manipulatif uygulamalarla bu bozuklukları düzeltmeye çalışan bir uygulamadır. Özellikle uterin ve sakral ligamentlerle sinir köklerini etkilediği ve böylece ağrının algılanmasının engellendiği düşünülmektedir (Coşkun ve Özdilek, 2017). Keskin ve arkadaşlarının (2016) yaptıkları araştırmada üniversite öğrencilerinin \%15.5 'nin PMS ile başetmede kayroplaksi yöntemini tercih ettiği saptanmışlardır. Kayropraksinin PMS yakınmaları üzerine etkisinin araştırıldı $\breve{~}$ randomize, plasebo kontrollü bir çalışmada ise kayropraksi uygulanan grupta plasebo grubuna göre anlamlı bir fark saptanamamıştır (Girman ve ark., 2003).

\section{Gıda Takviyeleri}

PMS'nin nedeni tam olarak bilinmemekle birlikte bazı vitamin ve minerallerin eksikliğinin PMS semptomlarına neden olduğu veya semptomları şiddetlendirdiği düşünülmektedir (Abdi ve ark., 2019).

Abdi ve arkadaşları (2019), sistematik derlemelerinde, D vitamini ve kalsiyum desteğinin veya bu iki mikro besleyici açısından zengin bir diyetin kullanımının PMS semptomlarını ortadan kaldırabileceğinden veya iyileştirebileceğinden bahsetmektedir. Kaewrudee ve arkadaşları (2018) sistematik derlemelerinde, Vitamin ve mineral takviyeleri PMS semptomlarını hafifletmede etkili olabileceğinden ve ayrıca vitamin veya mineral bakımından zengin diyetleri olan kadınlar arasında PMS insidansının düşük olduğunun kaydedildiğinden bahsetmektedir.

Fitoterapi, şifalı bitkilerin hastalıkların tedavisinde kullanılması esasına dayanmakta ve farmakoloji biliminin bir dalı olarak kabul edilmektedir. Premenstrual sendromda da bazı bitkiler ağrı kontrolünde yaygın olarak kullanılmaktadır. Bunlardan en sik kullanılan hayit bitkisinin (vitex agnus castus) premenstrual sendromun semptomları üzerinde etkili olduğu belirtilmektedir. Etkisini dopamin yoluyla, LH ve FSH'1 etkilemeden, prolaktin sekresyonunun düzenlemesiyle ilgili olduğu düşünülmektedir (Karaca ve Beji, 2015). Verkaik ve arkadaşlarının (2017) yaptıkları meta-analizde 14 çalışmanın 13'ünde vitex angus castusun premenstrual sendrom semptomlarına olumlu etkileri olduğu bildirilmiştir. Ayrıca sarı kantaron (St. John's Wort) bitkisi ve mabet ağacı (ginkgo) bitkisinin de kullanılan diğer bitkisel ürünler olduğu bildirilmektedir (Coşkun ve Özdilek, 2017). Yapılan bir çalışmada 19 PMS'li kadına iki menstrual siklus boyunca günlük $300 \mathrm{mg}$ sarı kantaron özü içeren tabletler verilmiştir ve sonuçta PMS sendrom skorlarının \%50 azaldığ saptanmıştır (Stevinson ve Ernst, 2001). Yapılan iki farklı çalışmada öğrencilerin PMS'de bitkisel ürünleri kullanma oranları \%66.3 ve \%28.6 olarak bulunmuştur (Keskin ve ark., 2016; Kırcan ve ark., 2012).

Dikkati başka yöne çekme, kişinin ağrı dışında farklı bir uyaranda odaklaştırmasını sağlayarak ağrı kontrolünde fayda sağlamaktadır. $\mathrm{Bu}$ yöntem kişinin ağrısını tamamıyla geçirmez ama ağrı eşiğini yükseltir, ağrıya toleransını arttırır. Dikkati başka yöne çekme yöntemleri ilgi çekici olmalı ve birden fazla duyuya hitap etmelidir. $\mathrm{Bu}$ yöntemler, puzzle ya da farklı oyunlar, film seyretme, konuşma, objeleri sayma, resim yapma ve şiir dinleme gibi etkinliklerdir (Özveren, 2011).

\section{Premenstrual Sendromda Hemşirelik Yönetimi \\ PMS'nin günümüzde halen etkin bir tedavisi bulunmamaktadır. PMS ile baş etmede kadınlar nonfarmakolojik yöntemler ile farmakolojik tedavi yöntemleri kullanılmaktadır. Fakat PMS ile baş etme de kadınların ilk sıradaki tercihi farmakolojik yöntemler olmaktadır (RCOG, 2017).}


İlk tercih edilen yöntem olan farmakolojik tedaviden önce, kadınlara PMS ile baş etme yöntemleri hakkında, bilgi verilmeli, kadınla iletişim kurulmalı ve ona destek olunmalıdır. Bu noktada hemşirenin rolü büyüktür (Karaca ve Beji, 2015). Hemşire hem birinci basamakta hem ikinci basamakta kadın ve ailesine bütüncül yaklaşım göstererek sorunlarına danışmanlık eder. PMS nedeniyle sağlık kuruluşuna başvuran kadınlardan tıbbi öykü, üreme sağlı̆ğ, menstrual ve PMS hikayesine yönelik sorular sorularak anamnez alır. Böylelikle kadında hangi semptomların daha sık yaşandığı, siklusun hangi fazında daha sık görüldüğü belirlenmiş olur. Anamnez alınırken, kadının kendini rahat ifade edebilmesi için uygun ortam yaratılmalı ve soruları cevaplanmalıdır (Taylor, 2005).

PMS ile baş etmede eğitimin büyük bir yeri vardır. Hemşire, eğitim ile PMS semptomlarının bir sorun olduğunu, gerektiğinde uzmana başvurması gerektiğini benimsetmeli ve ayrica semptomlarının azaltılması ya da önlenmesinde, bireyin sorumluluk alması ve kendi bakımına katılmasını sağlamalıdır (Karaca ve Beji, 2015).

\section{Sonuç}

PMS ile başetmede sağllk eğitimi çok önemlidir. Eğitim ile menstruasyonun normal bir durum ancak PMS'un bir sorun olduğu, gerektiğinde uzmana başvurma bilinci kazandırılmalıdır. Ayrıca kişiler kendilerinde görülen premenstrual semptomlarla baş etmede, ilk başvurulan yol olan analjezik kullanımından önce, sağlıklı yaşam ve premenstrual semptomları hafifletilmesi için gerekli girişimler hakkında desteklenmeli ve eğitim verilmelidir.

Özellikle öğrenci hemşirelere eğitimleri sırasında temel hemşirelik derslerinde ağrı, ağrı kontrolü ve uygulanabilecek farmakolojik olmayan tedaviler hakkında bilgi verilmelidir.
Araştırmanın Etik Yönü/ Ethics Committee Approval: Kaynaklar bölümünde kullanılan literatür gösterilmiştir .

Hakem/Peer-review: Dış hakem değerlendirmesi.

Yazar Katkısı/Author Contributions: Fikir/ kavram: HSÇ, NE; Tasarım: HSÇ, NE; Danışmanlık: NE; Kaynak tarama: HSÇ, NE; Makalenin Yazımı: HSÇ, NE; Eleştirel inceleme: NE.

Çıkar çatışması/Conflict of interest: Çalışmada herhangi bir çıkar çatışması söz konusu değildir.

Finansal Destek/Financial Disclosure: Çalışma için herhangi bir finansal destek alınmamıştır.

\section{Çalışma Literatüre Ne Kattı?}

- Premenstrual sendromda ağrı ve etkili faktörlerle ilgili bilgi verilmiştir.

- Premenstrual sendromda ağrı ile başetmede kullanılan farmakolojik ve nonfarmakolojik yöntemler hakkında bilgi verilmiştir.

- Premenstrual sendromda ağrı yönetimi konusunda sağlık personelinin rolü belirtilmiştir.

\section{Kaynaklar}

Abay H, Kaplan S. (2019). Current approaches in premenstrual syndrome management. Bezmialem Science, 7(2), 150-156.

Abdi F, Ozgoli G, Rahnemaie FS. (2019). A systematic review of the role of vitamin D and calcium in premenstrual syndrome . Obstetrics and Gynecology Science, 62(2),73-86.

Armour M, Ee CC, Hao J, Wilson TM, Yao SS, Smith CA. (2018). Acupuncture and acupressure for premenstrual syndrome. Cochrane Database of Systematic Reviews, $8,1-45$.

Arslan E, Dökmeci F. (1999). Premenstrual sendrom ve tedavisinde son görüşler. Ankara Üniversitesi T1p Mecmuas1, 52(4), 237-241.

Bolsoy N. (2008). Premenstrüel Distresin Hafifletilmesinde Refleksolojinin Etkinliğinin İncelenmesi. Doktora Tezi, Ege Üniversitesi, İzmir.

Cabığlu MT. (2008). Akupuntur ile ağrı kontrolü ve nörotransmitterler. Genel Tip Dergisi, 18(2), 93-98. 
Coşkun AM, Özdilek R. (2017). Premenstrual sendromda integratif uygulamaların kullanımı. Türkiye Klinikleri Obstetric-Women's Health and Diseases Nursing-Special Topics, 3(2), 7584.

Çatakoğlu H. (2016). 25 Yaş Üstü Kadınlarda Premenstrual Sendrom Görülme Sıklığ1 ve İlişkili Faktörler. Yüksek Lisans Tezi, Selçuk Üniversitesi, Konya.

Çöçelli L, Bacaksız B, Ovayolu N. (2008). Ağrı tedavisinde hemşirenin rolü. Gaziantep Tip Dergisi, 14, 53-58.

Dehnavi ZM, Jafarnejad F, Goghary SS. (2018). The effect of 8 weeks aerobic exercise on severity of physical symptoms of premenstrual syndrome: A clinical trial study. BMC Women's Health, 18(80). 1-7.

Duyan EC. (2007). İş ve yaşam tatmininde yoganın etkileri üzerine bir araştırma. Uludağ Üniversitesi İktisadi ve İdari Bilimler Fakültesi Dergisi, 26(1), 25-34.

Eğicioğlu H, Coşar E, Kundak Z, Pektaş M, Köken G. (2014). Premenstrual sendromun yaşam kalitesine olan etkileri, sosyodemografik özelliklerle ilişkili mi? Jinekoloji-Obstetrik ve Neonatoloji Tip Dergisi, 12(1), 10-17.

Erbil N, Bölükbaş N, Tolan S, Uysal F. (2011). Evli kadınlarda premenstrual sendrom görülme durumu ve etkileyen faktörlerin belirlenmesi. Uluslararası İnsan Bilimleri Dergisi, 8(1), 427438.

Erbil N, Karaca A, Kırış T. (2010). Investigation of premenstrual syndrome and contributing factors among university students. Turkish Journal Medical Sciences, 40(4), 565-573.

Frank RT. (1931). The hormonal causes of premenstrual tension. Archives of Neurology \& Psychiatry, 26(5),1053-1057.

Gençdoğan B, (2006). Premenstruel sendrom için yeni bir ölçek. Türkiye'de Psikiyatri, 8(2), 8286.

Girman A, Lee R, Kligler B. (2003). An integrative medicine approach to premenstrual syndrome. American Journal of Obstetrics and Gynecology, 188(3), 56-65.

Hasanpour M, Mohammadi MM, Shareinia H. (2019). Effects of reflexology on premenstrual syndrome: a systematic review and metaanalysis. BioPsychoSocial Medicine, 13, 25.
Heydari N, Abootalebi M, Jamalimoghadam N, Kasraeian M, Emamghoreishi M, Akbarzadeh M. (2018). Investigation of the effect of aromatherapy with Citrus aurantium blossom essential oil on premenstrual syndrome in university students: A clinical trial study. Complementary Therapies Clinical Practice, $32,1-5$.

İskender MD, Eren H. (2020). Examining nursing theses about acupressure for pain management in Turkey. Journal of Traditional Medical Complementary Therapies, 3(1), 40-46.

Işık H, Ergöl Ş, Aynığlu Ö, Şahbaz A, Kuzu A, Uzun M. (2016). Premenstrual syndrome and life quality in Turkish health science students. Turkish Journal of Medical Sciences, 46, 695701.

Jang SH, Kim D, Choi MS. (2014). Effects and treatment methods of acupuncture and herbal medicine for premenstrual syndrome/ premenstrual dysphoric disorder: Systematic review. BMC Complementary and Alternative Medicine, 14(11), 1-13.

Kaewrudee S, Kietpeerakool C, Pattanittum P, Lumbiganon P (2018). Vitamin or mineral supplements for premenstrual syndrome (protocol). Cochrane Database of Systematic Reviews, 1, 1-20.

Kamalifard M, Yavari A, Asghari-Jafarabadi M, Ghaffarilaleh G, Kasb-Khah A. (2017). the effect of yoga on women's prementrual syndrome: A randomized controlled clinical trial. International Journal of Women's Health and Reproduction Sciences, 5(3), 205-211.

Karaca P, Beji N. (2015). Premenstrual sendromun tanı ve tedavisinde kanıt temelli yaklaşımlar ve hemşirelik bakımı. Balıkesir Sağlık Bilimleri Dergisi, 4(3), 178-186.

Keskin T, Yeşilfidan D, Adana F, Okyay P. (2016). Aydın Sağlık Yüksekokulu öğrencilerinde premenstrual şikâyetler ve başa çıkma yöntemleri. Turkish Armed Forces Preventive Medicine Bulletin, 15(5), 382-388.

Kırcan N, Ergin F, Adana F, Arslantaş H. (2012). Hemşirelik öğrencilerinde premenstrual sendrom prevalansı ve yaşam kalitesi ile ilişkisi. Adnan Menderes Üniversitesi Tip Fakültesi Dergisi, 13(1), 19-25.

Kısa S, Zeyneloğlu S, Güler N. (2012). Üniversite öğrencilerinde premenstrual sendrom görülme sıklığ 1 ve etkileyen faktörler. Gümüşhane Üniversitesi Sağlık Bilimleri Dergisi, 1(4), 284297. 
Koçoğlu D, Özdemir L. (2011). Yetişkin nüfusta ağr1 ve ağrı inançlarının sosyo-demografik ekonomik özelliklerle ilişkisi. Ağrı, 23(2), 6470.

Lotfipur-Rafsanjani SM, Ravari A, Ghorashi Z, Haji-Maghsoudi S, Akbarinasab J, Bekhradi R. (2018). Effects of Geranium Aromatherapy Massage on Premenstrual Syndrome: A Clinical Trial. International Journal of Preventive Medicine, 5 (9), 98.

Matsumoto T, Asakura H, Hayashi T. (2013). Does lavender aromaterapy alleviate premenstrual emotional symptoms?:A randomized crossover trial. BioPsychoSocial Medicine, 7(12), 1-10.

Oskay Ü, Can G, Taş D, Sezgin Ö. (2008). Hemşirelik yüksekokulu öğrencilerinde görülen premenstrual sorunlar. İstanbul Üniversitesi Florence Nightingale Hemşirelik Dergisi, 16(63), 157-164.

Ovayolu Ö, Ovayolu N. (2019). Yoga uygulamalarında kanitlar. Hacettepe Üniversitesi Hemşirelik Fakültesi Dergisi, 6(1), 44-49.

Öztürk S, Tanrıverdi D. (2010). Premenstrual sendrom ve baş etme. Anadolu Hemşirelik ve Sağllk Bilimleri Dergisi, 13(3), 57-61.

Özveren H, Uçar H. (2009). Öğrenci hemşirelerin ağr1 kontrolünde kullanılan farmakolojik olmayan bazı yöntemlere ilişkin bilgileri. Sağlık Bilimleri Fakültesi Hemşirelik Dergisi,16(3), 59-72.

Özveren H. (2011). Ağrı kontrolünde farmakolojik olmayan yöntemler. Sağlık Bilimleri Fakültesi Hemşirelik Dergisi, 83-92.

Özveren H, Faydalı S, Özdemir S.(2016). Hemşirelerin ağrının farmakolojik olmayan yöntemlerle kontrolüne ilişkin bilgi ve uygulamalar1. Turkish Journal of Clinics and Laboratory, 7(4), 99-105.

Royal College of Obstetricians and Gynaecologists Green Top Guideline (2017). No 48. In: Panay $\mathrm{N}$, ed. The management of premenstrual syndrome, www.rcog.org.uk.

Reed GM, First MB, Kogan CS, Hyman SE, Gureje O, Gaebel W., et al. (2019). Innovations and changes in the ICD-11 classification of mental, behavioural and neurodevelopmental disorders. World Psychiatry, 18 (1), 3-19.

Sağlam HY, Orsal Ö. (2020). Effects of exercise on premenstrual symptoms: A systematic review. Complementary Therapies in Medicine, 48, 1-8.
Stephenson, NL, Dalton, JA. (2003). Using Reflexology For Pain Management: A Review Journal of Holistic Nursing, 21,179-191.

Stevinson C, Ernest E. (2001). Complementary /Alternative therapies for premenstrual syndrome: A systematic review of randomized controled trials. American Journal of Obstetrics and Gynecology, 185(1), 227-235.

Taşkın L. (2016). Üreme Siklusu Anomalileri, Doğum ve Kadın Sağlığı Hemşireliği, 9. Bask1. Ankara, Özyurt Matbaacılık. s.736-738.

Taylor D. (2005). Perimenstruel syndrom ve syndromes: guidelines for symptom management and self care. Obstetrics \& Gynecology, 5(5), 229-241.

Tsai SY. (2016). Effect of yoga exercise on premenstrual symptoms among female employees in Taiwan. International Journal of Enviromental Research and Public Health, 13, 721-732.

Turan N, Öztürk A, Kaya N. (2010). Hemşirelikte yeni bir sorumluluk alanı: Tamamlayıc terapi. Maltepe Üniversitesi Hemşirelik Bilim ve Sanat1 Dergisi, 3(1), 103-108.

Uluslararası Ağrı Araştırmaları Derneği, AĞRI: Klinik Güncellemeler.Erişim Tarihi:11.04.2020. https://www.iasppain.org/terminology?navItemNumber=576\#Pai $\mathrm{n}$.

Vaghela N, Mishra D, Sheth M, Dani VB. (2019). To compare the effects of aerobic exercise and yoga on Premenstrual syndrome. Journal of Education and Health Promotion, 24(8), 199.

Verkaik S, Kamperman AM, Van Westhrheman R, Schulte PFJ. (2017). The treatment of premenstrual syndrome with preparations of vitex agnus castus: A systematic review and meta-analysis. American Jynecology Obstetrics and Gynecology, 217(2), 150-166.

Wu WL, Lin TY, Chu IH, Liang JM. (2015). The acute effects of yoga on cognitive measures for women with premenstrual syndrome. The Journal of Alternative and Complementary Medicine, 21(6), 364-369. 